\title{
A long-term record of blended satellite and in situ sea-surface temperature for climate monitoring, modeling and environmental studies
}

\author{
Viva Banzon ${ }^{1}$, Thomas M. Smith ${ }^{2}$, Toshio Mike Chin ${ }^{3}$, Chunying Liu ${ }^{1,4}$, and William Hankins ${ }^{1,4}$ \\ ${ }^{1}$ NOAA National Centers for Environmental Information (NCEI), 151 Patton Ave., Asheville, NC 28801, USA \\ ${ }^{2}$ NOAA/STAR/SCSB/ESSIC University of Maryland, College Park, MD 20740, USA \\ ${ }^{3}$ Jet Propulsion Laboratory, California Institute of Technology, 4800 Oak Grove Dr., Pasadena, CA 91109, USA \\ ${ }^{4}$ Earth Resources Technology, 14401 Sweitzer Lane Suite 300, Laurel, MD 20707, USA \\ Correspondence to: Viva Banzon (viva.banzon@noaa.gov)
}

Received: 17 December 2015 - Published in Earth Syst. Sci. Data Discuss.: 19 January 2016

Revised: 5 April 2016 - Accepted: 8 April 2016 - Published: 28 April 2016

\begin{abstract}
This paper describes a blended sea-surface temperature (SST) data set that is part of the National Oceanic and Atmospheric Administration (NOAA) Climate Data Record (CDR) program product suite. Using optimum interpolation (OI), in situ and satellite observations are combined on a daily and $0.25^{\circ}$ spatial grid to form an SST analysis, i.e., a spatially complete field. A large-scale bias adjustment of the input infrared SSTs is made using buoy and ship observations as a reference. This is particularly important for the time periods when volcanic aerosols from the El Chichón and Mt. Pinatubo eruptions are widespread globally. The main source of SSTs is the Advanced Very High Resolution Radiometer (AVHRR), available from late 1981 to the present, which is also the temporal span of this CDR. The input and processing choices made to ensure a consistent data set that meets the CDR requirements are summarized. A brief history and an explanation of the forward production schedule for the preliminary and science-quality final product are also provided. The data set is produced and archived at the newly formed National Centers for Environmental Information (NCEI) in Network Common Data Form (netCDF) at doi:10.7289/V5SQ8XB5.
\end{abstract}

\section{Introduction}

Sea-surface temperature (SST) is an essential climate variable (ECV). The Global Climate Observing System (GCOS) project developed a list of ECVs to focus worldwide observation efforts on a limited set of variables that are climate relevant, technically feasible, and cost effective (Bojinski et al., 2014). Collectively, ECVs can help develop adaptation and mitigation strategies, assess risks, allow attribution and prediction, and support climate services. SST is useful for monitoring El Niño events and multi-decadal ocean changes. It is also relevant to quantification and modeling of many other aspects of climate such as air-sea interaction, ocean acidification to determine solubility of carbon dioxide, biophysical processes, and marine organism distributions. However, models require not just observations but also complete data fields, also referred to as analyses. Today, satellites offer high spatial and temporal coverage and are, therefore, the main source of SST observations. Additional processing is applied to satellite data to form analyses to allow for bias corrections and gap-filling and thereby increase spatiotemporal consistency.

The objective of this work is to describe the National Oceanic and Atmospheric Administration (NOAA) 1/4 daily Optimum Interpolation SST version 2 (or dOISST.v2, herein), an analysis that has been selected by the NOAA Climate Data Record (CDR) program as an operational CDR. This implies that the dOISST.v2 meets the definition of CDR put forward by the National Research Council (2004): it is of sufficient length, consistency, and continuity to determine climate variability. Furthermore, operational NOAA CDRs undergo a research-to-operations process to ensure system- 
atic production and quality assessment, thereby increasing the data set maturity in aspects like transparency, usability, and data preservation following metadata standards. A preliminary assessment using the maturity matrix of Bates and Privette (2012) indicated that dOISST.v2 has a high maturity in both science and applications, but it needed improvements in accessibility and transparency to users. As part of the effort to address this deficiency, this paper describes the dOISST.v2 CDR data set, in the context of its historical beginnings and evolution, current temporal and spatial characteristics, and data set formats and access, and provides examples of applications. Much of this information is publicly available but has not been summarized in a single document.

\section{Historical background}

Here, precursors to the dOISST.v2 that have evolved into the current CDR are briefly reviewed to highlight the original motivation and subsequent modifications. Historically, the widely-used name "Reynolds SST" has been applied to all current and precursor products, and is therefore ambiguous and not used here. Reynolds (1988) first introduced the concept of a blended SST analysis that takes advantage of the sea truth offered by in situ data and the high coverage of satellite data. Prior to 1980, ships were the only source of observations, and the spatial-temporal coverage was sufficient only for a coarse-scale analysis. Starting in late 1981, satellite-based SST observations became available daily from an infrared instrument, the Advanced Very High Resolution Radiometer (AVHRR), with Global Area Coverage (GAC) resolution at $\sim 4 \mathrm{~km}$. Using high-quality drifting buoys as reference, Reynolds (1988) found that monthly analyses, based on AVHRR SSTs alone or blended with in situ data, were slightly more accurate than those based on in situ data alone (with drifter data withheld). However, for infrared SSTs, notable satellite biases can occur under specific situations, e.g., at cloud edges or dust plumes (e.g., Bogdanoff et al., 2015; Vázquez-Cuervo et al., 2004). On a global scale, significant widespread biases have also been observed in the presence of volcanic aerosols, especially following the Mt Pinatubo and El Chichón eruptions, with AVHRR SSTs cooler than in situ observations by over $1{ }^{\circ} \mathrm{C}$ (Zhang et al., 2004; Reynolds, 1988, 1993). For these post-eruption periods, reliable global SST fields could be produced if in situ data were used to benchmark the satellite data to form blended analyses (Reynolds, 1988; Reynolds and Marisco, 1993). This large-scale benchmarking is also referred to as a "satellite bias adjustment".

Reynolds and Smith (1994) adopted the optimum interpolation (OI) method to increase the effective resolution of the blended analysis to $1^{\circ}$ and the temporal frequency from monthly to weekly and later to daily. This was the first time the name OISST was used. Along the marginal ice zone where observations were sparse, the interpolation was re- laxed to the freezing point of seawater $\left(-1.8^{\circ} \mathrm{C}\right)$. This was slightly modified in the follow-up version 2 (also referred to as OI.V2 in Reynolds et al., 2002), where a regression equation was used to estimate proxy SSTs from sea-ice concentrations. NCEP continues to produce the $1^{\circ}$ weekly OI.V2 for seasonal forecasting. The next section describes the original and current versions of dOISST. The core methodology for both versions is described in Reynolds et al. (2007). Appendix A presents minor improvements made by Reynolds in response to feedback from users (mostly added smoothing to reduce noise) and to extend the series back to 1981. Note that Appendix A contains material from Reynolds (2009), an online document, and has been included in this paper for preservation purposes.

\section{The climate data record}

Reynolds et al. (2007) introduced major methodological changes to increase the OISST resolution to the current daily, $1 / 4^{\circ}$ grid. The new bias correction scheme employed empirical orthogonal teleconnections (EOTs) modes rather than the Poisson method used in the weekly OI.V2. The use of EOTs also had the additional advantage of allowing estimation of the bias error. Moreover, the earlier OISST analyses used operational (i.e., near-real-time) satellite data, but for the $1 / 4^{\circ}$ daily OISST higher-quality input data sets reprocessed from the start of the mission were used preferentially over operational data. Most significant was the AVHRR Pathfinder reprocessing, which improved SST retrievals using nighttime buoy data to compute a revised set of coefficients for each NOAA satellite (e.g., Kilpatrick et al., 2001; Casey et al., 2010; Vázquez-Cuervo et al., 2010). However, the cold bias associated with the eruptions of El Chichón and Mt. Pinatubo remained a challenge even in the more recent AVHRR SST reprocessing efforts. Another change from the weekly OI.V2 was that the proxy SST calculation was restricted closer to the ice margin, i.e., where sea-ice concentrations exceed $50 \%$, to avoid potentially erroneous SST estimates in the more open waters, where the fit was much noisier.

Reynolds et al. (2007) referred to the above product as AVHRR-only, in reference to the source of satellite SSTs. The same paper describes a companion analysis that uses the same methodology but includes data from the Advanced Microwave Scanning Radiometer on the Earth Observing System (AMSR-E). This product, called AVHRR+AMSR, is not a CDR, due to the short period of record (2002 to 2011) of AMSR-E data. It should be noted that the Climate Forecast System Reanalysis (CFSR) at NCEP uses the same Reynolds et al. (2007) methodology to generate their initial SST fields (Saha et al., 2010, 2014), but may use different inputs (e.g., both infrared and microwave satellite SSTs, like the AVHRR+AMSR) over time and therefore will differ from this CDR. 
As discussed in Appendix A, the $1 / 4^{\circ}$ daily OISST was upgraded to version 2 primarily to increase temporal stability and to include Pathfinder AVHRR data from 1981 to 1985 that had become available (Casey et al., 2010). The treatment of in situ data was slightly modified. Historically, in situ observations were predominantly from ships. In the 21 st century, more accurate buoy data had become increasingly dominant over ship data, providing a better reference temperature. A constant $\left(\sim 0.14^{\circ} \mathrm{C}\right)$ was subtracted from the ship data to compensate for the global-average ship-buoy difference (Reynolds and Chelton, 2010; Appendix A). Modern ship measurements tend to be warmer because they typically use intake samples that can be warmed when taken into the ship engine room. However, there is much scatter in individual differences and better understanding of ship bias is needed to reduce the uncertainty in this correction. The net effect of this adjustment is that the daily OISST tends to be cooler than the weekly OI.V2 particularly in the 1980s and 1990s when ship data were dominant, making the long-term trend slightly steeper. Some of the differences between the current weekly OI.V2 and the current CDR, i.e., the dOISST.v2, including the impact on trends and climatologies, are discussed in greater detail in Banzon et al. (2014) and Huang et al. (2016).

\subsection{Data set description}

The daily OISST is available in netCDF and binary (FORTRAN IEEE big-endian) formats. In this paper, the archived netCDF files, publicly available at the National Centers for Environmental Information (NCEI) website, are described. However, the same data are repackaged and distributed elsewhere for specific projects or organizations such as the Group for High Resolution SST (or GHRSST) and Observations for Model Intercomparison Projects (Obs4MIPs), with accompanying metadata and documentation, but are not described here. The heritage binary format will be eventually phased out.

A single netCDF file contains four global gridded fields $(1440 \times 720)$ pertaining to 1 day. The primary variable is the analyzed SST (units in ${ }^{\circ} \mathrm{C}$; Fig. 1a). Since buoys are used as a reference, this is sometimes referred to as a "bulk" SST, at a nominal buoy depth of $1 \mathrm{~m}$. The SST input data types (AVHRR daytime, AVHRR nighttime, buoys, ships, proxy SST; Table 1) are first averaged to $1 / 4^{\circ}$ superobservations. The in situ data (consisting of the buoy and adjusted ship data) are collectively used to make large-scale adjustments to satellite data using the EOT modes. All data are merged during the interpolation, using the pre-computed error characteristics as weights. More details can be found in Reynolds et al. (2007). Grid points corresponding to land, permanent ice shelves, and most inland waters are not processed and assigned a missing value of -999 .

Three other gridded fields at the same $1 / 4^{\circ}$ spatial resolution complement the daily analysis. (a) dOISST

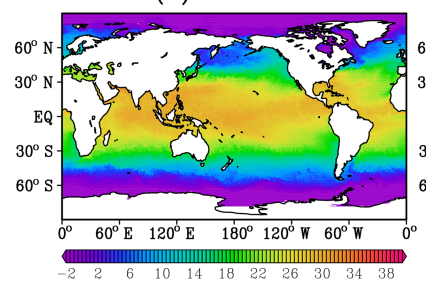

(c) dOISST error

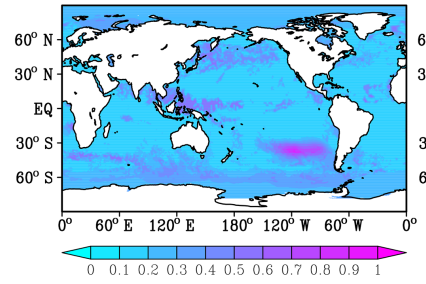

(b) dOISST anomaly

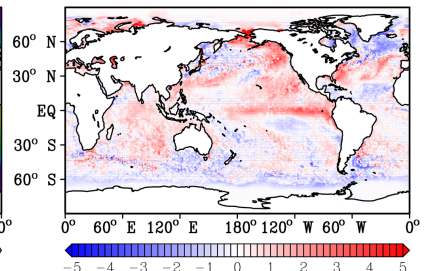

(d) Median sea ice conc

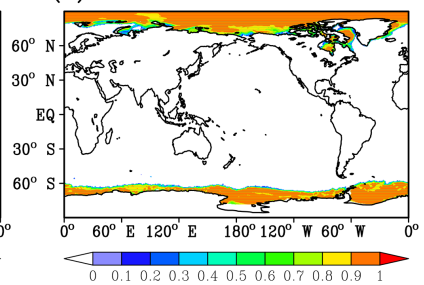

Figure 1. Examples of the four variables in a singles file: (a) dOISST.v2, (b) dOISST anomaly, (c) error, and (d) median seaice concentrations. Data are shown for 20 June 2015.

- Anomalies (i.e., the daily OISST minus the 1971-2000 climatological mean; units in ${ }^{\circ} \mathrm{C}$; Fig. 1b) represent departures from "normal" or average conditions. The anomalies are provided so users can easily compute climate indices, such as the NINO3.4 (Fig. 2a). The 1971-2000 climatology is partly based on an in situ analysis for the years that satellite data are not available (1971-1981) and on the weekly OISST for years satellite data are available from 1982 onward (Xue et al., 2003). A climatological mean computed from daily OISST (1982-2011) is now available and is more suitable to use with this data set, as explained in Banzon et al. (2014). It will be used in the next version. User should consider that with a long-term warming, a more recent period may produce a warmer climatological mean; thus, when subtracted from the analyzed SSTs, it produces cooler anomalies.

- The standard error (with units in ${ }^{\circ} \mathrm{C}$; Fig. 1c) provides a measure of uncertainty in the estimated SST, allowing users to exclude (using a threshold) or to minimize (using weights) the importance of grid point values with greater errors, as needed for the specific application, e.g., resource management, risk analysis, or assimilation into a model.

- The 7-day median of daily sea-ice concentrations (expressed as a real fraction from 0.0 to 1.0 ; Fig. 1d) is the basis of the proxy SST estimate in the marginal ice zone. Aside from reducing noise, the temporal median populates the time series in the early 1980s when satellite sea-ice observations were available only every other day. There are no sea-ice data from 4 December 1997 to 14 January 1998 . This field is effectively also an ice 
Table 1. Input data sets to the daily OISST version 2. The data sources are explained in detail in Reynolds et al. (2007). For version 1, ICOADS 2.1 was used.

\begin{tabular}{lll}
\hline Input type & Reprocessed or higher-quality data sets & Operational data sets \\
\hline Satellite (AVHRR SSTs) & Pathfinder 5.0/5.1 (1981-2006) & Navy (2007-present) \\
In situ SSTs & ICOADS 2.4 (1981-2006) & NCEP (2007-present) \\
Sea-ice concentrations & GSFC NASA (1981-2004) & NCEP (2005-present) \\
\hline
\end{tabular}

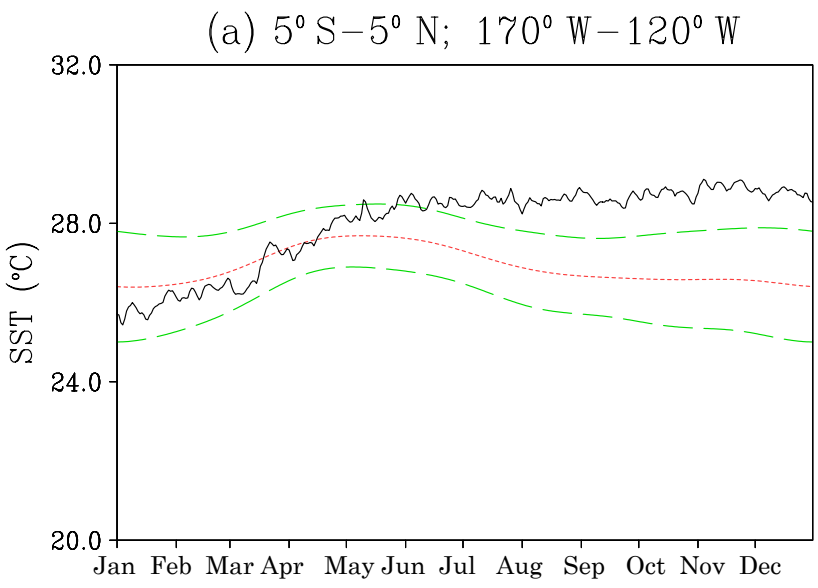

(b) $42^{\circ} \mathrm{N}-44^{\circ} \mathrm{N} ; 70^{\circ} \mathrm{W}-66^{\circ} \mathrm{W}$

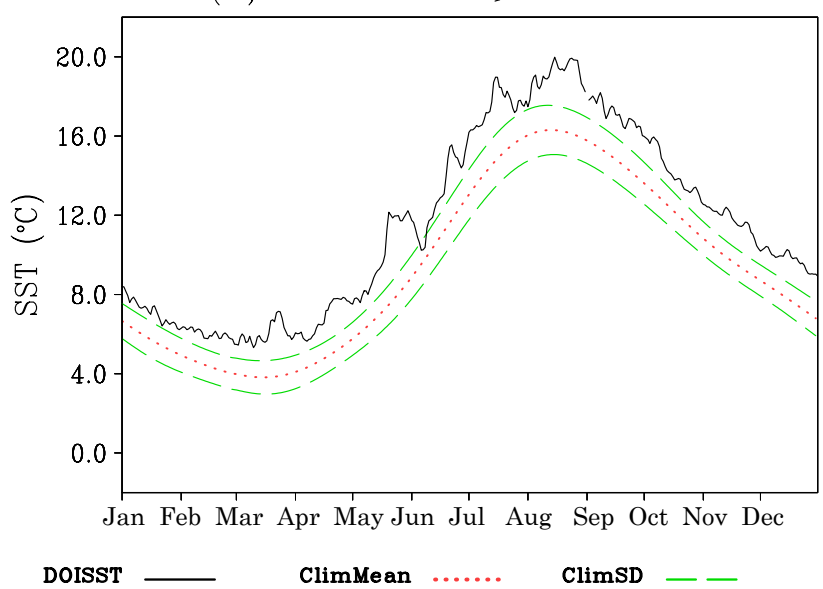

Figure 2. (a) Temporal progression of the 1997 daily OISST in the NINO3.4 region (solid line) and the 1982-2011 climatological mean (short dash) for the same area. The offset from the mean by plus and minus 1 standard deviation (long dash) shows characteristic variability. (b) Same but in 2012 in the Gulf of Maine (after Mills et al., 2013). Titles show coordinates used to compute the area weighted means.

mask when the user opts to exclude areas with high ice concentrations.

The input data sets to dOISST.v2 are listed in Table 1 and have been evaluated in more detail in Reynolds et al. (2007). While reprocessed inputs are used whenever possible, only operational data sets meet the low latency needs of the daily
Table 2. Platform time spans of AVHRR inputs to the daily OISST. Note that two satellites at a time are used beginning January 2007.

\begin{tabular}{lllll}
\hline Data set & Start date & End date & Platform & Sensor \\
\hline Pathfinder & 24 Aug 1981 & 3 Jan 1985 & NOAA-7 & AVHRR/2 \\
& 4 Jan 1985 & 7 Nov 1988 & NOAA-9 & AVHRR/2 \\
& 8 Nov 1988 & 13 Sep 1994 & NOAA-11 & AVHRR/2 \\
& 14 Sep 1994 & 21 Jan 1995 & NOAA-9 & AVHRR/2 \\
& 22 Jan 1995 & 11 Oct 2000 & NOAA-14 & AVHRR/2 \\
& 12 Oct 2000 & 31 Dec 2002 & NOAA-16 & AVHRR/3 \\
& 1 Jan 2003 & 4 Jun 2005 & NOAA-17 & AVHRR/3 \\
& 5 Jun 2005 & 31 Dec 2006 & NOAA-18 & AVHRR/3 \\
\hline Navy & 1 Jan 2006 & 31 Dec 2008 & NOAA-17 & AVHRR/3 \\
& 1 Jan 2007 & 15 Aug 2011 & NOAA-18 & AVHRR/3 \\
& 1 Jan 2009 & Present & MetOP-A & AVHRR/3 \\
& 16 Aug 2011 & Present & NOAA-19 & AVHRR/3 \\
\hline
\end{tabular}

updates. Users should be aware that sensor problems are typically cannot be addressed in near real time. The release date of the dOISST.v2 was November 2008. To minimize the impact of near-real-time sensor problems, data from two AVHRRs are used from 2007 onward (Table 2).

The analysis for the first day in the record used climatology as a first guess. For all other days the previous analysis is used as a first guess. For the daily update, a 1-day delayed analysis is produced. Two weeks later, after more data have become available, the analysis is repeated to produce higherquality "final" product. The final and preliminary runs can be identified in the global attributes of the netCDF file, and the preliminary filename also contains the word "preliminary". Only the "final" product is archived.

\subsection{Basic characterization}

The daily OISST is available for the full period of record from September 1981 to the present. The data set is similar to other global daily SST analyses in that monthly, seasonal, and multi-year averages can be computed on global, regional, and local scales. For climate applications, the daily OISST is unique because it extends from late 1981 to the present and therefore spans over 30 years, often cited as the minimum period needed to distinguish interannual variations from longterm variations. The characteristic seasonal SST cycle, represented here by the 1982-2011 climatological mean, varies by location. In the tropics, it is exemplified by the NINO3.4 region (Fig. 1a), where the seasonal signal is weak. The start of 
the 1997 El Niño event is marked by SSTs that are more than 1 standard deviation greater than the climatological mean for over 3 months. A stronger seasonal cycle occurs in the temperate zone, as seen in the Gulf of Maine (Fig. 2b). The SSTs over the entire year 2012 exceed the climatological mean plus 1 standard deviation. The daily progression shows particularly elevated May-June temperatures, which initiated a season of anomalous lobster catch (Mills et al., 2013). Of course, these atypical events can also investigated by examining the anomalies.

Long time series are ideal for computing multi-decadal trends. On an annual scale, the 1982 to 2014 global linear trend using dOISST is $\sim 0.12^{\circ} \mathrm{C}$ per decade. The wintertime trend is slightly smaller $\left(0.09^{\circ} \mathrm{C}\right.$ per decade using only January monthly averages; Fig. 3a) than in summertime $\left(0.14^{\circ} \mathrm{C}\right.$ per decade using only July monthly averages; Fig. 3b). The $1 / 4^{\circ}$ resolution data allow trends to be computed on more local scales, but comparisons should always be made with in situ measurements, if available. The daily SST information can be used to generate other climate-relevant parameters. For example, the number of days that SSTs are above a threshold, also known as degree days, is an indicator of thermal stress for corals. In fact, many ecological responses to a changing ocean can be modeled in terms of the cumulative effect of daily temperatures on growth, reproduction, recruitment, and the like.

Global validation of the dOISST using buoy and ship data is not an independent assessment because in situ data are used to make the product, although the amount of satellite data incorporated is much greater. Comparisons with other SST analyses would have the same issue since most analyses also use in situ data. With that caveat, Reynolds and Chelton (2010) showed that, relative to buoys, the dOISST.v2 and other analyses all exhibit regional variability in performance, reflecting their methodological differences. For the dOISST.v2, the root-mean-square error relative to the buoys is about $0.3^{\circ} \mathrm{C}$. Reynolds and Chelton (2010) also found that the product degrades in quality during prolonged periods of no data, e.g., seasonally cloud-covered areas such as the Gulf Stream in winter. Analyses that included microwave data had better results when infrared retrievals were not available, because of the added data coverage. However, when infrared data were available, the addition of microwave data reduced the quality of the resulting analyses because microwave SSTs are less accurate. In any case, an analysis is not necessarily the best source of SST for a single point in space or time because it is a smoothed product. The advantage is that where there are no observations, an analysis provides interpolated values and, over time, a consistent long-term record. It should be noted that the analysis is also useful as a reference field for identifying bad data and is therefore used in several satellite algorithms for quality control. It also serves as a first guess or as ancillary data for computing parameters that require a known temperature field. (a) Daily OISST global average: Jan

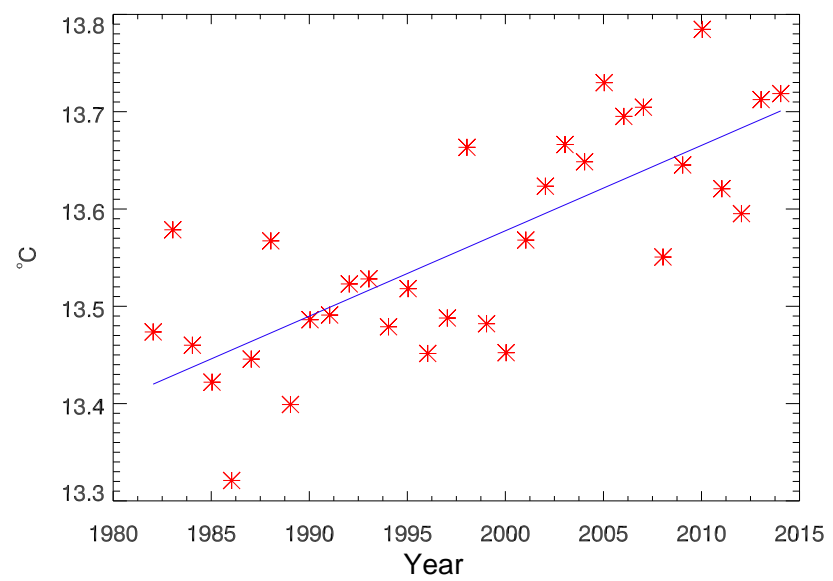

(b) Daily OISST global average: Jul

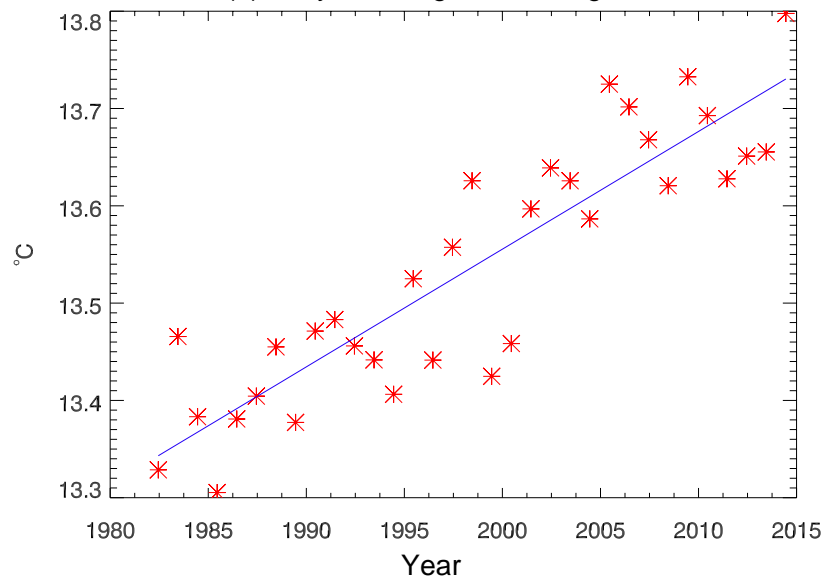

Figure 3. Global OISST trends (1982-2014) using (a) January monthly means only and (b) July monthly means only.

Argo data, which are not used as an input to dOISST, can also be used for validation. However, Argo observations are available only after 2000 and are located deeper $(\sim 4 \mathrm{~m})$ than surface buoy measurements. As agreed on by the GHRSST community, most SST analyses do not incorporate Argo data in order to have a common independent validation data set. Martin et al. (2012) used Argo data for the year 2010 to compare different near-real-time SST data sets, including the preliminary dOISST (defined in Sect. 3.1), and their collective median. All data sets had a standard deviation below $0.7 \mathrm{~K}$ relative to Argo data. Most, including dOISST, had an overall bias between 0.2 to $0.4 \mathrm{~K}$. Certainly, as the Argo data set grows, it might be possible to withhold only a portion for validation and use the rest in the analysis. For a future version of dOISST, Argo data could improve data coverage in areas with sparse ship and buoy data such as the Tropical Pacific, where moored buoy data were degraded for some years.

In terms of feature resolution, i.e., the ability of an analysis to reproduce mesoscale ocean features and capture SST 


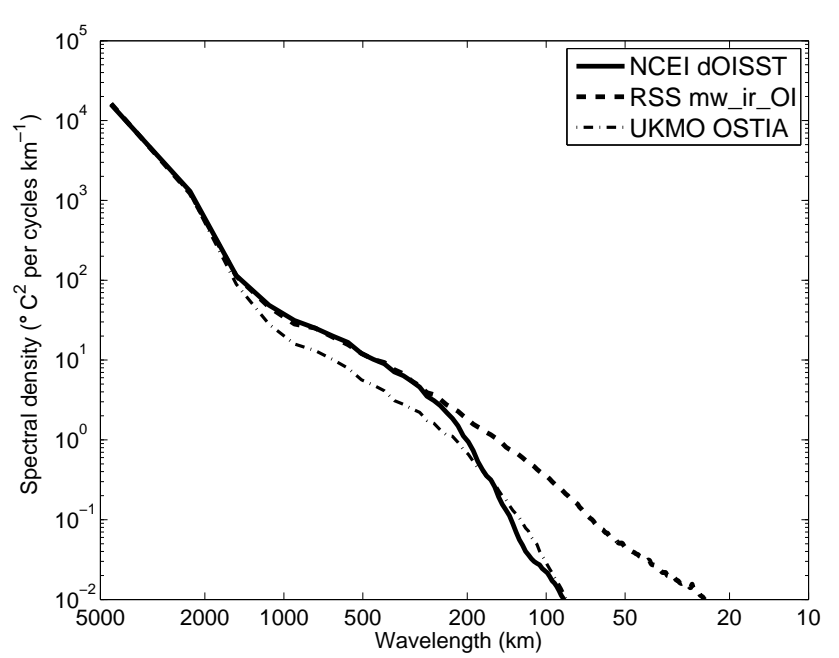

Figure 4. Power spectra of three analyzed SST fields from the first 2 months of 2016. See text for explanation of data sets used. At smaller scales, the spectrum of the RSS product that ingests high-resolution inputs (1 km MODIS SSTs) continues to display the same spectral slope into the smaller-scale range. MODIS SSTs are available only from 1999 .

gradients, Reynolds et al. (2007) showed dOISST performs well. Reynolds and Chelton (2010) also found that feature resolution of an analysis is not necessarily related to the grid size. To illustrate this point here, the power spectral densities of three SST data sets examined by Reynolds and Chelton (2010) are shown (Fig. 4). The plot is similar to Reynolds and Chelton (2010) except that the latest versions of the three data sets (from the first 2 months of 2016) are used and the spectra are smoother because they are the average of several areas rather than a single area, in order to provide a global representation of each data set. The three products shown differ in grid resolutions: dOISST is on a $1 / 4^{\circ}$ grid, the Operational SST and Sea Ice Analysis (OSTIA) is on a $1 / 20^{\circ}$ grid (doi:10.5067/GHOST-4FK01; UK Met Office, 2005), and the Remote Sensing Systems (RSS) analysis is computed on a $1 / 11^{\circ}$ grid (doi:10.5067/GHMWI-4FR01; Remote Sensing Systems, 2008). All spectra indicate identical large-scale (and perhaps seasonal) SST patterns at wavelengths larger than $1500 \mathrm{~km}$. All spectra also show similar slopes (of -2) in the mesoscale range down to about $300 \mathrm{~km}$ wavelength. At shorter scales $(<200 \mathrm{~km})$, the power spectra for dOISST and OSTIA are nearly identical even when the latter has a finer grid size. In comparison, the RSS product resolves finer-scale features as indicated by the more gradual drop off.

In general, the higher-resolution SST analyses combine higher-resolution infrared data (with low spatial coverage due to inability to penetrate clouds) and lower-resolution but more spatially complete microwave data, which have quasiall-weather coverage (e.g., Vázquez-Cuervo et al., 2013). The ability to provide good feature resolution in a particular area is constrained by the availability of finer resolution $(\sim 1 \mathrm{~km})$ infrared data and the use of a methodology that preserves that information. Thus, even though the average spectra may show an ability to resolve fine features, products tend to be smoother in areas where only microwave data are available (Vázquez-Cuervo et al., 2013). High-resolution artifacts may also be created due to insufficient data (Reynolds and Chelton, 2010).

\section{Conclusions}

A long-term sea-surface temperature climate data record consisting of in situ and satellite data blended daily on a $1 / 4^{\circ}$ grid is available for climate monitoring, modeling, validation, and a wide range of other applications. The data set uses AVHRR data from 1981 to the present, bias-adjusted relative to situ data. This produces a time series that is more consistent than satellite infrared retrievals alone. This CDR is produced, distributed, and generated by the NCEI, a newly formed entity that is a merger of three NOAA data centers including the National Climatic Data Center (NCDC), which originally produced this data set.

Compared to the precursor weekly OISST at NCEP, the CDR has many updates including higher spatial resolution, reprocessed inputs, and adjustment of ship data to match buoys. The CDR is also used as an ancillary field in reprocessed and operational satellite algorithms including the Pathfinder AVHRR SST, Tropical Rainfall Measuring Mission (TRMM) rain rate, and Aquarius salinity. The CDR version of the dOISST.v2 is available in netCDF format doi:10.7289/V5SQ8XB5 (Reynolds et al., 2008).

\section{Data availability}

The dOISST.v2 data set described in this paper is available at the National Centers for Environmental Information, under the name "NOAA Optimum Interpolation 1/4 Degree Daily Sea Surface Temperature (OISST) Analysis, Version 2" with doi:10.7289/V5SQ8XB5. The data are also available in a different format at the Physical Oceanography Distributed Active Archive Center (PODAAC) at the Jet Propulsion Laboratory (JPL) under the name "GHRSST Level 4 AVHRR_OI Global Blended Sea Surface Temperature Analysis", with doi:10.5067/GHAAO-4BC01. The two other SST products used for comparisons in Fig. 4 are also available at the PODAAC. The "GHRSST Level 4 mw_ir_OI Global Foundation Sea Surface Temperature analysis" has doi:10.5067/GHMWI-4FR01. The "GHRSST Level 4 OSTIA Global Foundation Sea Surface Temperature Analysis" has doi:10.5067/GHOST-4FK01. 
Table A1. The linear least squares fit of the ship and buoy data shown in Fig. A2.

\begin{tabular}{lll}
\hline Period & Slope & Intercept \\
\hline $1989-1997$ & 0.988 & $-0.136{ }^{\circ} \mathrm{C}$ \\
$1998-2006$ & 0.924 & $-0.118^{\circ} \mathrm{C}$ \\
$1989-2006$ & 0.965 & $-0.133{ }^{\circ} \mathrm{C}$ \\
\hline
\end{tabular}

Appendix A: What's new in version 2

By Richard W. Reynolds, 30 January 2009

\section{A1 Introduction}

The purpose of this note is to discuss the upgrade of the version 1 (v.1) daily OI SST analysis (Reynolds et al., 2007) to version 2 (v.2). These changes are relatively small and mostly consist of additional temporal smoothing. In addition, preliminary Pathfinder data (following Kilpatrick et al., 2001) have been processed using NOAA-7. This allows the analysis to be extended backward in time. The daily OI AVHRRonly v2 analysis now begins on 1 September 1981; v1 began on 4 January 1985.

\section{A2 Modifications version 2}

Other than the extension of v2 backward in time to September 1981, there are seven analysis changes in v. 2 .

\section{A2.1 Temporal smoothing of daily OI data}

Day-to-day analysis differences are discussed by Reynolds et al. (2007) on page 5491 and illustrated there in Fig. 13 by four partial snap shots of the Gulf Stream from the AMSR and the AVHRR instruments during 1 day. The day-to-day differences are due to a limited number of observations in regions of high variability. Observations are limited by the spatial width of the satellite swath as well as by cloud cover for AVHRR and by precipitation and the vicinity of land for AMSR.

In v.1 observations used in the daily OI were taken from the day analyzed. To temporally smooth the analysis, 3 days of data were used where the off days (the day before and after the analysis day) have doubled noise-to-signal ratios (standard deviation) compared to the center day. The doubled noise-to-signal ratio reduces the impact of the off days.

See Reynolds et al. (2007) page 5480 for a discussion of noise-to-signal ratios.

To verify the impact of this smoothing, 43 moored buoys were selected which had daily data for at least $99 \%$ of the days for the period 2003-2005. These buoys were located off the coasts of North America and Europe and in the tropical Pacific and Atlantic. Auto spectra were computed for the
Table A2. Comparison of different versions.

\begin{tabular}{llll}
\hline Feature & V.1 & Interim V.2 & Final V.2 \\
\hline Time delay & 1 day & 1 day & 14 days \\
Days of data in OI & 1 day & 1 day & 3 days \\
Ship bias correction & No & Yes & Yes \\
Preliminary zonal bias & No & Yes & Yes \\
Smoothing of EOT modes & No & No & 5 days \\
Days of data in EOT bias & 7 days & 7 days & 15 days \\
AMSR data improved & No & Yes & Yes \\
Start AVHRR-only OI & Jan 1985 & Replaced & Sep 1981 \\
Start AMSR+AVHRR OI & Jun 2002 & Replaced & Jun 2002 \\
\hline
\end{tabular}

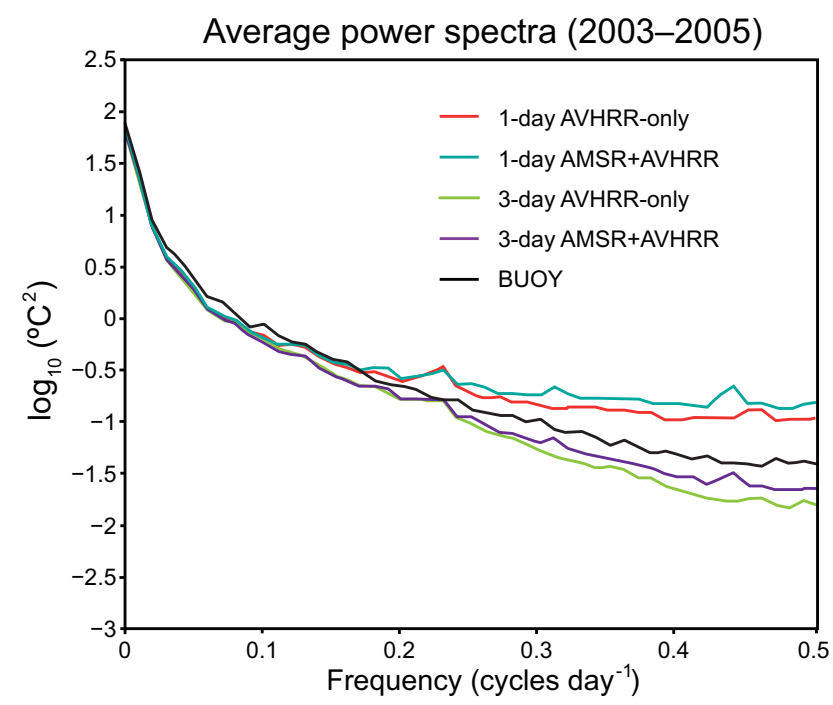

Figure A1. Globally averaged daily spectra for 2003-2005 computed at 43 moored buoy locations and averaged. "AVHRR-only" and "AMSR+AVHRR" indicate daily OI spectra using either 1 day or 3 days of data. "Buoy" indicates spectra using daily buoy data.

2003-2005 period at each of buoy locations from the dailyaveraged buoy data and from four daily OI analyses: the OI using either only AVHRR or AMSR and AVHRR data with 1 day or 3 days of data. The spatial averaged spectra are shown in Fig. A1. The low frequencies ( $<0.2$ cycles per day) are nearly identical. The buoy data and the 3-day OI analyses have similar variances at higher frequencies although the buoy variance is being slightly higher. However, the 1-day OI analyses have considerably larger variance at higher frequencies than the others.

\section{A2.2 Ship SST biases with respect to buoys}

As discussed in Reynolds et al. (2007), the random and bias errors of ship SST data are larger than the random and bias errors of buoy SSTs. Furthermore, as shown in Fig. A2 from Reynolds et al. (2002), the coverage of buoys tends to increase with time while the coverage of ship tends to decrease. To determine the variability of a globally averaged 


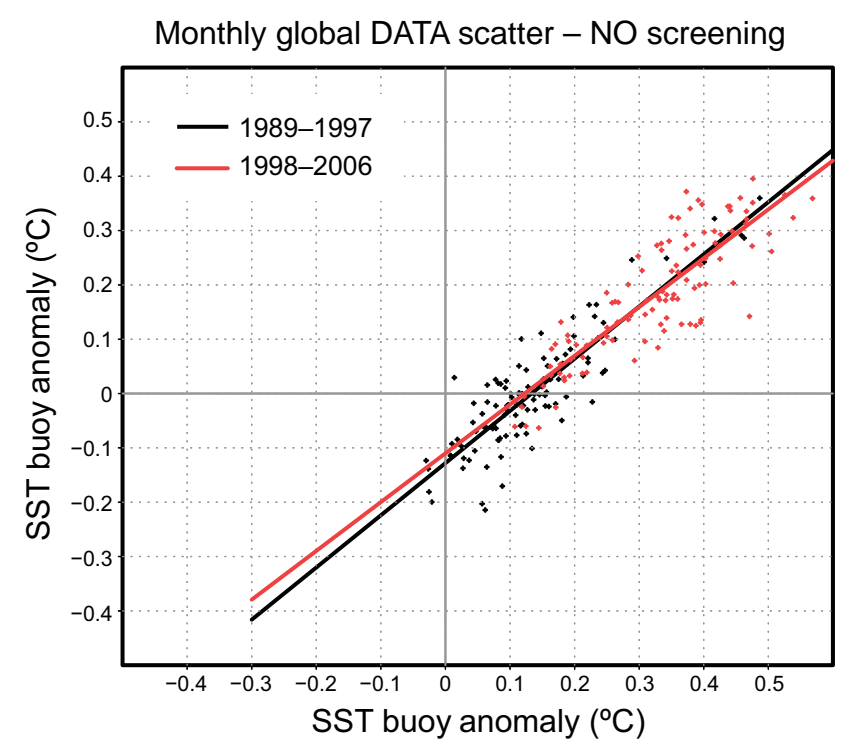

Figure A2. Scatter plot of global collocated average monthly ship vs. buoy anomaly for January 1989-December 2006. The first 9 years are shown in the black and the second 9 years in red. Least squares linear fits for the two periods are also shown.

bias, monthly averaged ship biases were computed with respect to buoys. However, even with temporal smoothing, differences occurred at irregular intervals and did not seem to be related to seasonal or El Niño-Southern Oscillation events.

Monthly scatter plots of the collocated average global ship and buoy anomaly SSTs are shown in Fig. A2 for two 9year periods. The least squares linear fit for the two periods is also shown with the slope and intercept given in Table A1. These results strongly suggest that a spatial and temporal constant bias correction is needed. However, finer space and time corrections do not seem to be possible with the limited in situ data available. The fit indicates that the average intercept is $-0.13^{\circ} \mathrm{C}$. When the average global difference are computed directly, the average buoy minus ship difference is found to $-0.14^{\circ} \mathrm{C}$. As differences of $0.01{ }^{\circ} \mathrm{C}$ are not significant, $0.14^{\circ} \mathrm{C}$ was subtracted from all ship data before they are used in the satellite bias correction and in the OI analysis. No correction was made for the buoy data.

\section{A2.3 Zonal satellite bias correction}

As discussed on page 5482 of Reynolds et al. (2007), the daytime and nighttime satellite observations are adjusted to the daily average of the in situ (ship and buoy) data. This is done using EOTs which are similar to rotated empirical orthogonal functions. The method produces an anomaly SST EOT for in situ data, $I(x, y)$, and an anomaly SST EOT for satellite data, $S(x, y)$, where $x$ and $y$ are the longitude and latitude coordinates, respectively. The bias, $B$, is defined as the difference: $B(x, y)=I(x, y)-S(x, y)$. Only EOT modes which are adequately sampled by both in situ and satellite
Difference: Jul 2006

(Path EOT V2) - (Navy-17 EOT V2)
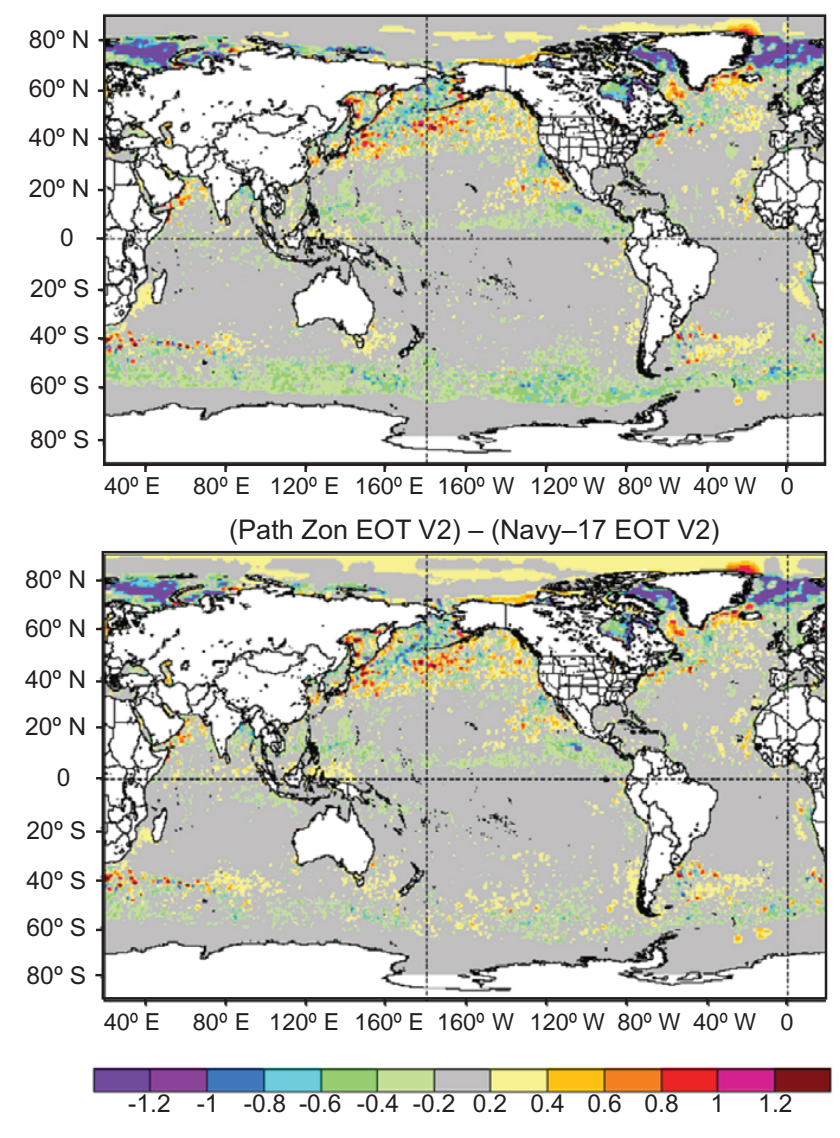

Figure A3. Average July 2006 difference between the daily AVHRR-only OI using Pathfinder NOAA-17 data and operational Navy NOAA-17 data. All versions use bias-corrected satellite data. In the top panel the Pathfinder daily OI uses no preliminary zonal bias correction; in the bottom panel the Pathfinder daily OI uses a preliminary zonal bias correction.

data are used. In regions where there are no EOT modes, the anomalies and hence the biases are 0 .

Figure 12 from Reynolds et al. (2002) shows that Pathfinder AVHRR SSTs have cold biases with respect to operational Navy AVHRR. If the bias correction has a residual, long-term differences will indicate it. This is shown in the upper panel of Fig. A3 for July 2006. The tropical differences suggest possible cloud Pathfinder contamination in the Intertropical Convergence Zone. However, there are also high latitude differences where in situ data are sparse. To correct these differences smoothed zonal in situ minus satellite differences, $z(y)$, were computed directly from the data. These differences were subtracted from the satellite data before the EOT procedures and then added back onto the biases. This zonal correction has no net impact on the bias correction unless there are no EOT modes. In that case, $B(x, y)=z(y)$. The lower panel shows the difference between the two daily 


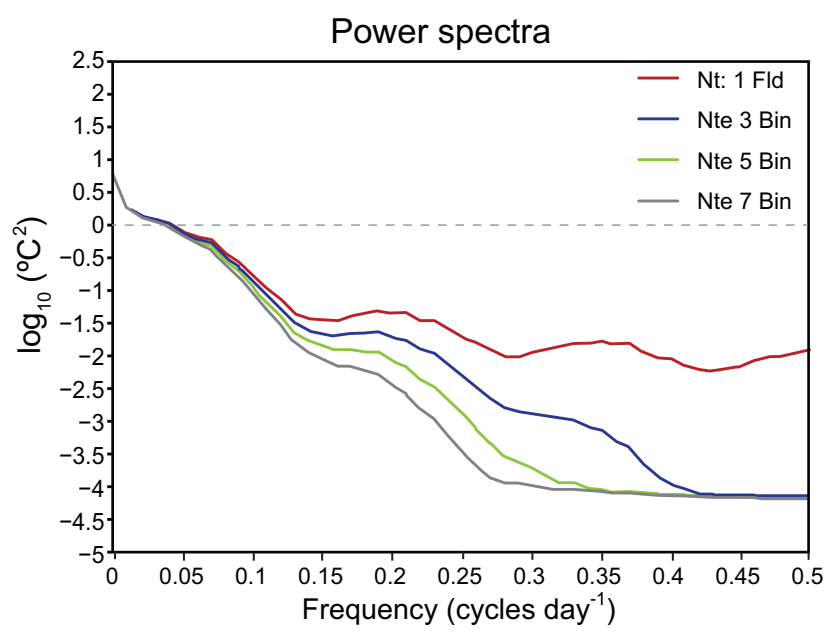

Figure A4. Spatially averaged nighttime AVHRR bias correction spectra for 2000-2005. Binomial three-point, five-point, and sevenpoint temporal smoothing are shown; an unsmoothed version is labeled "Nt 1 Fld".

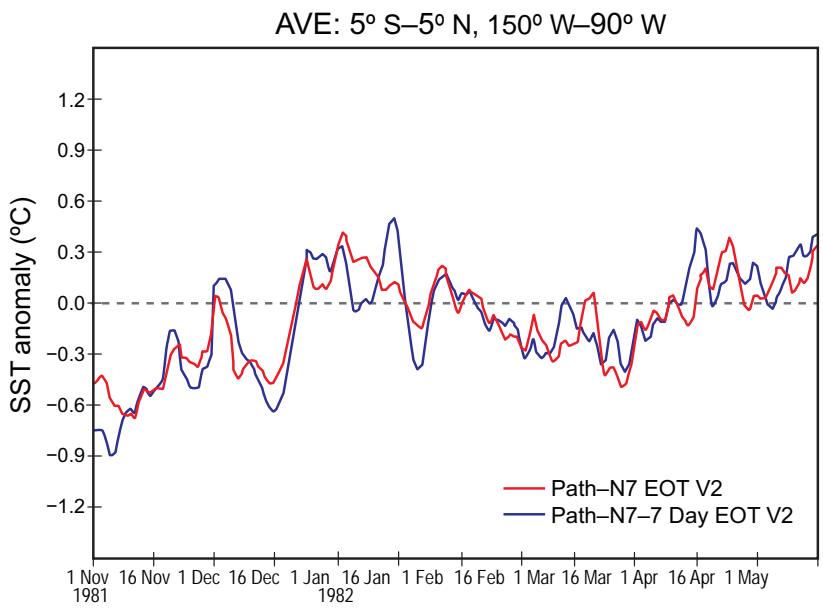

Figure A5. Daily OI Nino-3 anomalies using EOT bias correction with 15 and 7 days of data. "N-7" indicates that NOAA-7 satellite SST data are used.

OI versions with the zonal correction. Here the zonal correction reduces the difference between 60 and $40^{\circ} \mathrm{S}$. It has little impact outside of the region even at high northern latitudes. Although there are differences at high latitudes which are not corrected by the EOT method, the biases are not zonal between 70 and $80^{\circ} \mathrm{N}$ so $z(y)$ is small there.

\section{A2.4 Temporal smoothing of satellite bias corrections}

The biases, $B(x, y)$, use 7 days of in situ and satellite data. These biases tend to be temporally noisy because the in situ data are sparse. In particular, jumps in the biases can occur as time changes and data either appear or disappear from the 7-day window.
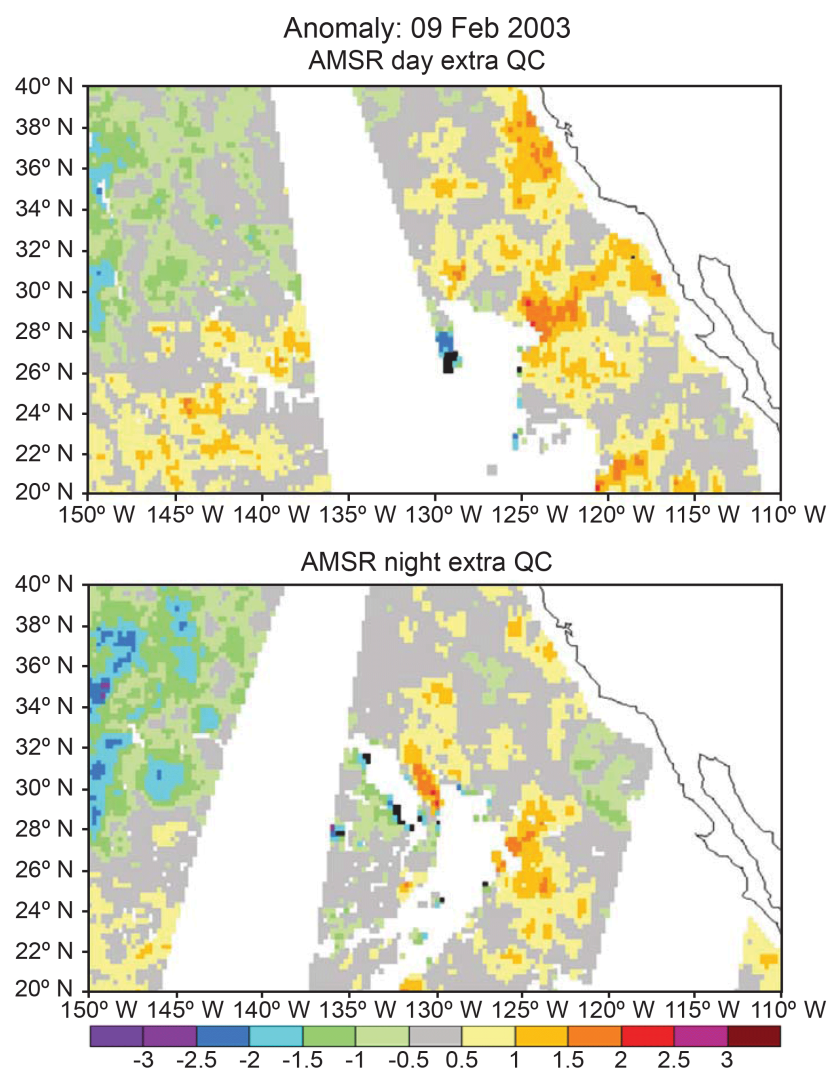

Figure A6. AMSR extra quality-controlled SST data anomalies for 9 February 2003. The black regions show where data have been rejected by the extra quality control.

A binomial filter using 3, 5, and 7 days was then used on the mode weights of the original 7-day bias corrections. To examine the impact, spectra were computed over a 6-year period. The spectral results were very similar for both day and night. The globally averaged nighttime bias spectrum is shown in Fig. A4 for each binomial filter along with the original unsmoothed spectrum. All spectra show some ringing which is roughly at frequency multiples of roughly oneseventh cycles per day and due to the use of 7 days of data.

All the binomial filters reduce the variance at higher frequencies. It is not clear which version of the binomial filter would be best. However, the 5-day binomial filter seemed to be a reasonable compromise and was selected.

\section{A2.5 Increased number of days and data used in the bias correction}

Comments from John Stark, UK Met Office, and preliminary processing of NOAA-7 data indicated that the daily OI Niño3 time series were noisy with periods of about a week due to the EOT bias correction. The time series was especially noisy in the earlier half of the record before 1990 when buoy data were sparse. Additional filtering of the weights (medi- 
ans, nine-point box car, etc.) did not give much improvement. Thus, the EOT data period was increased from 7 to 15 days. Figure A5 shows that the Niño-3 anomalies using 7 and 15 days. In particular note the 7-day anomaly sign change centered near 15 January 1982. It is clear that this type of variability is reduced using 15 days.

\section{A2.6 Improved AMSR quality control}

Figure 12 from Reynolds et al. (2007) shows that the daily OI interpolates the analysis across the region of missing AMSR data near $130^{\circ} \mathrm{W}$ and $35^{\circ} \mathrm{N}$. This region was missing AMSR data due to precipitation contamination which results in extreme values on the edges of this region. Chelle Gentemann (personal communication, 2007) used improved quality control to flag AMSR data with questionable SST obs. The results for 9 February 2003 are shown in Fig. A6. The questionable SSTs (in black) are only a small part of the total observations. The AMSR extra quality control reduces the strong noise shown in Fig. 12 from Reynolds et al. (2007).

\section{A2.7 Improved AMSR quality control}

There were some errors in the quarter-degree land/sea mask. The major change was to eliminate some inland fiords by setting these points to land. These points occurred at the edge of the Arctic in Russia and Greenland, in the Inside Passage area of Alaska south of Juneau, and in the Strait of Magellan. In these regions winter sea ice was often the only data available to the analysis and often lead to large anomalies in summer. In addition, one badly represented small island in the Red Sea and one spurious island off Antarctica near $75^{\circ} \mathrm{S}$ and $0.5^{\circ} \mathrm{W}$ were eliminated and set to ocean.

\section{A3 Final comments}

The use of 3 days of data in the OI and smoothing of the modes in the bias correction is not possible in near real time. Thus, two versions will be run: a real-time interim version followed by a final version after a 2-week delay. The interim version uses 1 day of in situ and satellite data in the OI with a satellite bias correction using 7 days (one sided) of data and without smoothing of the EOT modes. The final version uses 3 days (centered) of in situ and satellite data in the OI with a satellite bias correction using 15 days (centered) of data and smoothing of the EOT modes over 5 days (centered). Both versions have a ship bias correction, a preliminary zonal correction of satellite data, and improved quality control of the AMSR data. The interim version is replaced by the final version when the final version is computed. The daily OI using AVHRR only is available from September 1981 to present; the daily OI with AMSR + AVHRR is available from June 2002 to present. Table A2 indicates the differences among version 1 and the interim and final version 2 . 
Author contributions. All authors contributed to the text. V. Banzon wrote the draft, with significant text added by T. Smith. M. T. Chin performed the spectral analysis for Fig. 4 and provided accompanying text. Processing details were provided by C. Liu and B. Hankins, who ran the operational production.

Acknowledgements. The authors would like to thank R. W. Reynolds (retired), H.-M. Zhang, and G. Peng for providing comments that greatly improved this paper. R. W. Reynolds also authored the material presented in Appendix A and gave permission to include it in this article. Members of the OISST Integrated Products team, including C. Hutchins, P. Jones, R. McFadden, V. Toner, and D. Wunder, helped meet CDR program requirements for transition and maintenance of dOISST.v2.

Edited by: G. M. R. Manzella

\section{References}

Banzon, V. F., Reynolds, R. W., Stokes, D., and Xue, Y.: A 1/4 spatial resolution daily sea surface temperature climatology based on a blended satellite and in situ analysis, J. Climate, 27, 82218228, doi:10.1175/JCLI-D-14-00293.1, 2014.

Bates, J. J. and Privette, J. L.: A maturity model for assessing the completeness of climate data records, EOS Trans. AGU, 44, 441, doi:10.1029/2012EO440006, 2012.

Bogdanoff, A. S., Westphal, D. L., Campbell, J. R., Cummings, J. A., Hyer, E. J., Reid, J. S., and Clayson, C. A.: Sensitivity of infrared sea surface temperature retrievals to the vertical distribution of airborne dust aerosol, Remote Sens. Environ., 159, 1-13, doi:10.1016/j.rse.2014.12.002, 2015.

Bojinski, S., Verstraete, M., Peterson, T. C., Richter, C., Simmons, A., and Zemp, M.: The Concept of essential climate variables in support of climate research, applications, and policy, B. Am. Meteorol. Soc., 95, 1431-1443, doi:10.1175/BAMS-D-13-00047.1, 2014.

Casey, K. S., Brandon, T. B., Cornillon, P., and Evans, R.: The Past, Present and Future of the AVHRR Pathfinder SST Program, in: Oceanography from Space: Revisited, edited by: Barale, V., Gower, J. F. R., and Alberotanza, L., Springer, doi:10.1007/97890-481-8681-5_16, 2010.

Huang, B., Liu, C., Banzon, V. F., Zhang, H. M., Karl, T. R., Lawrimore, J. H., and Vose, R. S.: Assessing the impact of satellite observations in sea surface temperature trends, Geophys. Res. Lett., doi:10.1002/2016GL068757, in press, 2016.

Kilpatrick, K. A., Podesta, G. P., and Evans, R.: Overview of the NOAA/NASA advanced very high resolution radiometer Pathfinder algorithm for sea surface temperature and associated matchup database, J. Geophys. Res., 106, 9179-9198, 2001.

Martin, M., Dash, P., Ignatov, A., Autret, E., Banzon, V., Beggs, H., Brasnett, B., Cayula, J.-F., Chao, Y., Cummings, J., Donlon, C., Gentemann, C., Grumbine, R., Ishizaki, S., Maturi, E., McKenzie, B., Reynolds, R., and Roberts-Jones, J.: Group for high resolution SST (GHRSST) analysis fields inter-comparisons: part 1. A GHRSST multi-product ensemble (GMPE), Deep-Sea Res. Pt. II, 77-80, 21-30, 2012.
Mills, K. E., Pershing, A. J., Brown, C. J., Chen, Y., Chiang, F.-S., Holland, D. S., Lehuta, S., Nye, J. A., Sun, J. C., Thomas, A. C., and Wahle, R. A.: Fisheries management in a changing climate: Lessons from the 2012 ocean heat wave in the Northwest Atlantic, Oceanography, 26, 191-195, doi:10.5670/oceanog.2013.27, 2013.

National Research Council: Climate Data Records from Environmental Satellites: Interim Report, The National Academies Press, Washington, DC, doi:10.17226/10944, 2004.

Remote Sensing Systems: GHRSST Level $4 \mathrm{mw}$ _ir_OI Global Foundation Sea Surface Temperature analysis, Ver. 1.0. PO.DAAC, CA, USA, doi:10.5067/GHMWI-4FR01 (last access: 11 March 2016), 2008.

Reynolds, R. W.: A real-time global sea surface temperature analysis, J. Climate, 1, 75-87, doi:10.1175/15200442(1988)001<0075:ARTGSS>2.0.CO;2, 1988.

Reynolds, R. W.: Impact of Mount Pinatubo aerosols on satellite-derived sea surface temperatures, J. Climate, 6, 768-774, doi:10.1175/15200442(1993)006<0768:IOMPAO>2.0.CO;2, 1993.

Reynolds, R. W., Banzon, V. F., and NOAA CDR Program: NOAA Optimum Interpolation 1/4 Degree Daily Sea Surface Temperature (OISST) Analysis, Version 2, 1981-present, NOAA Climatic Data Center, doi:10.7289/V5SQ8XB5 (last access: 6 June 2015), 2008.

Reynolds, R. W.: What's New in Version 2, OISST Webpage, http://www.ncdc.noaa.gov/sites/default/files/attachments/ Reynolds2009_oisst_daily_v02r00_version2-features.pdf, 2009.

Reynolds, R. W. and Chelton, D. B.: Comparisons of daily sea surface temperature analyses for 2007-08, J. Climate, 23, 35453562, doi:10.1175/2010JCLI3294.1, 2010.

Reynolds, R. W. and Marsico, D. C.: An improved real-time global sea surface temperature analysis, J. Climate, 6, 114-119, doi:10.1175/1520-0442(1993)006, 1993.

Reynolds, R. W. and Smith, T. M.: Improved global sea surface temperature analyses, J. Climate, 7, 929-948, doi:10.1175/15200442(1994)007, 1994.

Reynolds, R. W., Rayner, N. A., Smith, T. M., Stokes, D. C., and Wang, W.: An improved in situ and satellite SST analysis for climate, J. Climate, 15, 1609-1625, doi:10.1175/15200442(2002)015<1609:AIISAS>2.0.CO;2, 2002.

Reynolds, R. W., Smith, T. M., Liu, C., Chelton, D. B., Casey, K. S., and Schlax, M. G.: Daily high-resolution-blended analyses for sea surface temperature, J. Climate, 20, 54735496, doi:10.1175/JCLI-D-14-00293.1, 2007.

Saha, S., Moorthi, S., Pan, H., Wu, X., Wang, J., Nadiga, S., Tripp, P., Kistler, R., Woollen, J., Behringer, J., Liu, H., Stokes, D., Grumbine, R., Gayno, G., Wang, J., Hou, Y., Chuang, H., Juang, H., Sela, J., Iredell, M., Treadon, R., Kleist, D., Van Delst, P., Keyser, D., Derber, J., Ek, M., Meng, J., Wei, H., Yang, R., Lord, S., Van Den Dool, H., Kumar, A., Wang, W., Long, C., Chelliah, M., Xue, Y., Huang, B., Schemm, J., Ebisuzaki, W., Lin, R., Xie, P., Chen, M., Zhou, S., Higgins, W., Zou, C., Liu, Q., Chen, Y., Han, Y., Cucurull, L., Reynolds, R. W., Rutledge, G., and Goldberg, M: The NCEP Climate Forecast System Reanalysis, B. Am. Meteorol. Soc., 91, 1015-1057, doi:10.1175/2010BAMS3001.1, 2010.

Saha, S., Moorthi, S., Wu, X., Wang, J., Nadiga, S., Tripp, P., Behringer, D., Hou, Y., Chuang, H., Iredell, M., Ek,M., Meng, J., 
Yang, R., Mendez, M., van den Dool, H., Zhang, Q., Wang, W., Chen, M., and Becker, E.: The NCEP Climate Forecast System Version 2, J. Climate, 27, 2185-2208, doi:10.1175/JCLI-D-1200823.1, 2014.

Vázquez-Cuervo, J., Armstrong, E., and Harris, A.: The effect of aerosols and clouds on the retrieval of infrared sea surface temperatures, J. Climate, 11, 3921-3933, 2004.

Vázquez-Cuervo, J., Armstrong, E. M., Casey, K. S., Evans, R., and Kilpatrick, K.: Comparison between the Pathfinder Versions 5.0 and 4.1 sea surface temperature datasets: A case study for high resolution, J. Climate, 23, 1047-1059, doi:10.1175/2009JCLI2839.1, 2010.

Vázquez-Cuervo, J., Dewitte, B., Chin, T. M., Armstrong, E. M., Purca, S., and Alburqueque, E.: An analysis of SST gradients off the Peruvian Coast: The impact of going to higher resolution, Remote Sens. Environ., 131, 76-84, 2013.
UK Met Office: GHRSST Level 4 OSTIA Global Foundation Sea Surface Temperature Analysis, Ver. 1.0. PO.DAAC, CA, USA, doi:10.5067/GHOST-4FK01 (last access: 11 March 2016), 2005.

Xue, Y., Smith, T. M., and Reynolds, R. W.: Interdecadal changes of 30-yr SST normals during 1871-2000, J. Climate, 16, 16011612, doi:10.1175/1520-0442-16.10.1601, 2003.

Zhang, H. M., Reynolds, R. W., and Smith, T. S.: Bias Characteristics in the AVHRR sea surface temperature, Geophys. Res. Lett., 31, L01307, doi:10.1029/2003GL018804, 2004. 